\title{
Sport Brand Architecture: Branding Effects Associated with the Creation of an Umbrella Brand
}

\author{
By Daniel Friesner \\ Carl S. Bozman ${ }^{+}$ \\ Faith A. Valentet
}

\begin{abstract}
Why should a sport organization create an umbrella brand? Such a brand extension within a product category or across product categories is common, yet there is an absence of research exploring the plausible effects associated with the creation of such a brand. This conclusion is problematic because many umbrella branding related consequences may not be positive. This paper develops a model of sport umbrella branding which identifies conditions where a sport organization may find it beneficial to employ an umbrella brand and the circumstances where such branding should instead be deemphasized. To do so, we construct a theoretical model and examine the strategic choices of one non-profit sport organization to create an umbrella brand within this context. Our findings are threefold. First, the decision to umbrella brand is distinct from the firm's objectives when the decision is not to pursue umbrella branding. Other considerations beyond profit orientation guide this decision. But decisions to adopt umbrella branding inherently include profit status. Moreover, the firm's profit-seeking objectives may reveal valuable information about the firm's pecking order of the firm's most valued brands. Second, the benefits associated with umbrella branding are greater when a sport organization can coordinate activities that facilitate brand synergy across related joint products, e.g. operations. Lastly, subsumed brands should contribute to the brand equity of the umbrella brand, e.g. increase rather than diminish favorability or quality perceptions. Umbrella branding does not appear to be as an effective strategy when a subordinated product is perceived to be of variable quality or there is a poor perceptual fit across similarly branded products.
\end{abstract}

Keywords: Brand architecture, umbrella branding, decision model, not-for-profit sport organizations.

\section{Introduction}

Sport organizations often do not operate in a highly competitive environment (Anonymous 2010, Mills and Winfree 2016). Rather, they exhibit local monopoly power or, in some cases, operate in oligopolistic or monopolistically competitive markets. Many of these organizations have established corporate holding

\footnotetext{
*Associate Professor, North Dakota State University, USA.

†Professor, Gonzaga University, USA.

tProfessor, North Idaho College, .
} 
companies, which manage multiple product lines (including other sporting events) that are branded using the same brand elements.

There is a reasonably well developed literature that discusses the rationale for, and competitive consequences of, umbrella branding (Pepall and Richards 2002). This literature suggests that umbrella branding can be used to accomplish several ends, including, but not limited to reducing risk, increasing potential market share, and enhancing the synergy of consumer perceptions across product lines, e.g. reducing the expense associated with the introduction of a new product (Montgomery and Wernerfelt 1992, Hakenes and Peitz 2008, Moorthy 2012). Most of the existing umbrella branding literature; however, examines firm behavior exclusively in retail shopping environments (Erdem and Chang 2012, Amrouche et al. 2014).

As an illustration, brand extensions within a product category and umbrella branding across retail product categories have been shown to reduce risk perceptions when the parent brand is strong or the quality of the extension is consistent with consumer expectations (Montgomery and Wernerfelt 1992, Erdem and Chang 2012). Umbrella branding does not appear to be an effective risk reduction strategy when the parent brand is perceived to be of variable quality or there is a poor perceptual fit between branded products (Moorthy 2012, Amrouche et al. 2014).

Compared to sport environments, retail markets are inherently more competitive, exhibit product lines that are more consistently addressed through umbrella branding, and have multiple products each of which are expected to contribute a unique stream of profit and/or stock of wealth to investors (Erdem and Chang 2012). Concomitantly, many sport organizations feature at least some product lines whose primary motivation may not be strictly profit maximizing (Thibault et al. 1993, Doherty and Murray 2007). Traditional conceptualizations of umbrella branding (which are characterized using game theory models of competitive behavior) may not apply to sport organizations (which exhibit market power) as consequence of these discrepant features. As a result, little is known about the strategic motivations underlying branding decisions in sport organizations.

To address this issue, we first provide a case study of a sport organization with monopoly power that utilizes umbrella branding across all of its product lines, some of which seek to maximize economic profit, while others are better viewed as net expenses (in an economic sense) to the firm. Yet the latter products still contribute to the umbrella brand. Next, a theoretical model of umbrella branding is proposed and solved that is generally consistent with the case study. When interpreted within the context of the case study, the model's results provide testable hypotheses about a number of considerations underlying umbrella branding decisions. 


\section{Case Study: Spokane Hoops}

Spokane Hoops was created in late 2017 as the umbrella brand for an organization that hosts a variety of regional basketball activities. The organization's primary basketball venture is an annual 3-on-3 basketball tournament known as Hoopfest. Since its establishment in 1990, Hoopfest, has grown from a small community based event to a large regional enterprise (Bozman et al. 2010, Kurpis et al. 2010, Friesner et al. 2016). The three-day event recently attracted over 25,000 players, 225,000 spectators, and 3000 volunteers (Schnell 2014). Spectators and participants attend the event from across the United States and several other countries in order to enjoy what is perhaps the largest 3-on-3 basketball tournament in the world. The International Olympic Committee just recently authorized the inclusion of 3-on-3 basketball as an official medal sport for the 2020 Olympic Games (Gartland 2017). Spokane Hoops has certainly contributed to the growing popularity and acceptance of 3-on-3 basketball.

Spokane Hoops contributes to the basketball community in a number of other ways, some of which are primarily profit-maximizing endeavors (again, from an economic profit perspective), while others are more philanthropic in nature. For example, Spokane Hoops will host a regional qualifier for the The Basketball Tournament (TBT), a for-profit national 5-on-5 basketball competition that features many former college and professional basketball players. TBT teams may be sponsored and the winning team will receive a $\$ 2,000,000$ cash prize (Ogden 2018). Teams who wish to participate can purchase a quarter of the slots available, tickets to each TBT game are sold, and many of the TBT games will be broadcast on ESPN. The winner of the Spokane Hoops qualifying TBT round will advance to the sweet sixteen of the seventy-two team event (Neyland 2018a).

On the other hand, Spokane Hoops sponsors the regional qualifiers for USA Basketball youth 5-on-5 national championships (Neyland 2018b). The expense associated with hosting 8th grade boys' and girls', 13U boys' and girls', and $12 \mathrm{U}$ boys' and girls' events is unlikely to be fully met by sponsorship revenue, team fees, ticket sales, and broadcast fees. USA Basketball is the national governing body for basketball operating under the auspices of the United States Olympic Committee.

Spokane Hoops also sponsors a variety of other basketball related programs, including (but not limited to) a competitive Amateur Athletic Union (AAU) basketball league, the Ignite (formerly the Midnight) Basketball Association, coach and player basketball clinics, and a version of the Spokane Hoopfest tournament held in Las Vegas, Nevada. The latter is an extension of the current Hoopfest model to another location, and falls within the organization's traditional core business. Most of the former product lines generate limited revenue and the costs associated with the implementation of those activities tautologically and substantially exceed any revenues earned.

Spokane Hoops has partnerships with other basketball-related organizations that may require additional subsidies. For example, Spokane Hoops partners with the Spokane Youth Sports Association to provide a developmental basketball 
league for second and third grade elementary students. This league helps prepare young people to participate in other youth basketball leagues, e.g. AAU, which begins in the fourth grade. The Spokane Hoops partnership with The Basketball Tournament, TBT, lies at the other end of the basketball development spectrum.

Since its inception, Spokane Hoops has helped construct basketball courts in regional public parks and donated over a million dollars to local charitable organizations such as Special Olympics and community centers. Spokane Hoops' business-oriented goal can therefore probably be better described as regional market dominance (share) rather than strict profitability. Thus, while all product lines may utilize the Spokane Hoops brand or brand elements, only a few product lines are likely to generate positive net revenue. The rationale and appropriate method for implementing an umbrella brand such as Spokane Hoops in this situation is neither obvious nor previously investigated in the sport literature.

\section{Umbrella Branding Model in a Not Strictly Profit-Maximizing Firm}

For the sake of parsimony, consider a not-strictly profit-maximizing firm that produces two distinct products (that may or may not be perceptually correlated within a subset of consumers). Additional distinct product lines are a straightforward extension of the two product model. The first product is the firm's main source of revenue. In each period the firm produces $\mathrm{X}$ units of this good, the firm charges an average price $\mathrm{P}$ and (excluding branding) incurs a per unit cost $\mathrm{C}$. These per unit costs should be interpreted in an economic, rather than an accounting, perspective. The quantity produced is the result of the firm's price point and its branding efforts. Let total expenditures to branding product $\mathrm{X}$ be denoted by $\mathrm{N}$.

The second product may or may not contribute positive (economic) profit to the firm. In each period, the firm produces Y units of this good. It charges a per unit price of $\mathrm{q}$, and producing $\mathrm{Y}$ generates an average cost (not including branding expenditures) of $\mathrm{k}$ per unit. The quantity produced is also a function of the firm's branding activities. Let total branding expenditures on product $Y$ be denoted by $\mathrm{n}$. Therefore, adopting the general structures suggested by Brook (2005) and Dube et al. (2005), profit for each product line is given by:

$(\mathrm{P}-\mathrm{C}) * \mathrm{X}-\mathrm{N}$

$(\mathrm{q}-\mathrm{k})^{*} \mathrm{Y}-\mathrm{n}$

Of particular interest is whether the firm engages in product specific branding or umbrella branding. If the firm brands each of its product lines separately, then each branding expenditure for one product line (which are defined as $\mathrm{B}_{\mathrm{X}}$ and $\mathrm{B}_{\mathrm{Y}}$ for $\mathrm{X}$ and $\mathrm{Y}$, respectively) contribute solely to that product line. In such cases we follow Brooks (2005) and specify the following demand functions:

$X=a-b P+f_{X}$

$\mathrm{Y}=\alpha-\beta q+\gamma B_{Y}$ 
$\mathrm{B}_{\mathrm{X}}=\mathrm{N}^{0.5}$

$\mathrm{B}_{\mathrm{Y}}=\mathrm{n}^{0.5}$

where $\mathrm{a}, \mathrm{b}, \mathrm{f}, \alpha, \beta$, and $\gamma$ are parameters (each of which is assumed to be positive); and the remaining variables are as defined previously. The imposition of a nonlinear impact of total branding expenditures on that product's demand ensures diminishing returns to branding expenditures. We note in passing that any exponent on the unit interval can ensure diminishing marginal returns. The value of 0.5 was chosen solely to ensure tractable and parsimonious solutions. An extension of the current model using more general representations of diminishing returns is left as a suggestion for future research.

Concomitantly, if Spokane Hoops practices umbrella branding, then we have

$\mathrm{X}=\mathrm{a}-\mathrm{bP}+\mathrm{fU}$

$\mathrm{Y}=\alpha-\beta \mathrm{q}+\gamma \mathrm{U}$

where $\mathrm{U}$ is combined branding efforts for both product brands on the demand for each product. Note that branding expenditures for each product, $\mathrm{N}$ and $\mathrm{n}$, continue to impact costs for its own product line. The major difference is that both promote a similar brand, which then allows marketing expenditures for one product line to impact the demand for another product line. For simplicity, we define:

$\mathrm{U}=\mathrm{N}^{0.5}+\mathrm{n}^{0.5}$

Of critical interest is whether the firm engages in separate or umbrella branding. This is particularly important when the production of the second good may or may not, in and of itself, generate net income or net wealth for the firm. In a sports event planning firm, this may include building public infrastructure (in the case of Hoopfest, funding the construction of basketball courts at local community parks), or by providing programming to disadvantaged community members (i.e., the Ignite Basketball league). Since it is unclear as to whether the second product line generates positive economic profit, we choose the following parsimonious functional form:

$\Pi=\mathrm{w}^{*}[(\mathrm{P}-\mathrm{C}) * \mathrm{X}-\mathrm{N}]+(1-\mathrm{w})[(\mathrm{q}-\mathrm{k}) * \mathrm{Y}-\mathrm{n}]$

Under this formulation, the firm's objective is to maximize a weighted average of economic profit generated by both activities, where $\mathrm{w}$ indicates this weight (which is assumed to be a proper proportion). If a firm solely values total profit maximization, $\mathrm{w}=1 / 2$, and profit generated by either product line is treated as equally valuable to the firm. If $\mathrm{w}$ moves away from $1 / 2$, it relatively values the profit generated by one line over another. This, for example, may facilitate less than optimal economic profit derived from a (we presume the second) product line.

The crucial issue is whether the firm brands the products jointly under a single umbrella or separately. To address this issue, we solve the model twice: once when 
there is no umbrella branding, and once where umbrella branding occurs. We then compare the optimal solutions under both regimes.

\section{Case 1: Separate Branding}

In this case, the firm chooses $\mathrm{P}, \mathrm{q}, \mathrm{N}$ and $\mathrm{n}$ to maximize the following objective function:

$$
\Pi=\mathrm{w}^{*}\left[(\mathrm{P}-\mathrm{C}) *\left(\mathrm{a}-\mathrm{bP}+\mathrm{fN}^{0.5}\right)-\mathrm{N}\right]+(1-\mathrm{w})\left[(\mathrm{q}-\mathrm{k})^{*}\left(\alpha-\beta \mathrm{q}+\gamma \mathrm{n}^{0.5}\right)-\mathrm{n}\right]
$$

First order necessary conditions are:

$$
\begin{aligned}
& \frac{\delta \Pi}{\delta P}=w\left(a-2 b P+f N^{0.5}+b C\right)=0 \\
& \frac{\delta \Pi}{\delta N}=w\left(0.5(P-C) f N^{-0.5}-1\right)=0 \\
& \frac{\delta \Pi}{\delta q}=(1-w)\left(\alpha-2 \beta q+\gamma n^{0.5}+\beta k\right)=0 \\
& \frac{\delta \Pi}{\delta n}=(1-w)\left(0.5(q-k) \gamma n^{-0.5}-1\right)=0
\end{aligned}
$$

Note that second order conditions to secure a maximum hold so long as ( $\mathrm{P}$ C) $>0,(\mathrm{q}-\mathrm{k})>0$ and the signs of the parameters are as assumed previously. Solving for the four choice variables yields:

$$
\begin{aligned}
& P *=C+\frac{2(a-b C)}{4 b-f^{2}} \\
& N *=\left(\frac{f(a-b C)}{4 b-f^{2}}\right)^{2} \\
& q *=k+\frac{2(\alpha-\beta k)}{4 \beta-\gamma^{2}} \\
& n *=\left(\frac{\gamma(\alpha-\beta k)}{4 \beta-\gamma^{2}}\right)^{2}
\end{aligned}
$$

The solutions given by (11) - (14) are consistent with traditional economic models of non-profit firm behavior with multi-output production (Kesteloot and Voet 1998). The optimal price of the first product line $(\mathrm{P})$ is equal to the average costs of production plus an adjustment factor. To ensure that both a positive solution for $\mathrm{P}$ and to ensure that second order conditions hold, the adjustment factor must be positive, which means that $(a-b C)$ and $\left(4 b-f^{2}\right)$ must have the same sign. The term a-bC characterizes the maximum quantity demanded for product $\mathrm{X}$, less costs (due to decreased quantity demanded) due to a change in $\mathrm{P}$. The denominator of the adjustment factor, $\left(4 \mathrm{~b}-\mathrm{f}^{2}\right)$, characterizes the crosseffect of branding efforts on pricing structure. A positive term for the latter expression suggests that the diminishing returns to branding eventually allows the pricing structure effect to dominate the branding effect. Because the magnitude of the firm's average costs, weighted by the marginal effect of a price change on the quantity demanded, is likely to be much smaller than the maximum quantity demanded in the market, we assume for simplicity that a $>$ bC. Similarly, and by 
extension that $4 \mathrm{~b}>\mathrm{f}^{2}$ (i.e., at the optimum, diminishing returns to branding is substantial).

Concomitantly, the solution for branding expenditures, $\mathrm{N}$, is unambiguously positive. The magnitude of optimal branding expenditures depends on the relative magnitudes of $(a-b C)$ and $\left(4 b-f^{2}\right)$, as described previously, weighted by the parameter $\mathrm{f}$ which characterizes the marginal impact of an increase in branding on the quantity demanded for product X. Clearly, larger values for the parameter $\mathrm{f}$ increase the effectiveness of branding, which leads to greater branding expenditures. Similarly, if the firm does not experience substantial diminishing returns to branding, the denominator of the expression is smaller, and branding expenditures are larger (and vice versa for greater diminishing returns to branding). Finally, the larger is the value $a-b C$, the more effective pricing strategies are to increase profitability (holding all else constant) which reduces the need for branding and reduces branding expenditures.

Similar intuition holds for the optimal price and branding expenditures for product line Y. By definition, each of the solutions in (11) - (14) must be positive and meet the second order conditions. For price $\mathrm{q}$, this requires pricing above average cost $\mathrm{k}$, which further requires $(\alpha-\beta k)$ and $\left(4 \beta-\gamma^{2}\right)$ to have the same (presumably positive) sign. The former term characterizes the maximum quantity demanded for product $\mathrm{Y}$, less costs (due to decreased quantity demanded) due to a change in q. The latter term characterizes the cross-effect of branding efforts for product $\mathrm{Y}$ on its pricing structure. A positive term for the latter expression suggests that the diminishing returns to branding eventually allows the pricing structure effect to dominate the branding effect. Analogous to the previous discussion, we assume that $\alpha>\beta k$ and $4 \beta>\gamma^{2}$. Like $\mathrm{N}$, the solution for $\mathrm{n}$ is unambiguously positive. The magnitude of optimal branding expenditures depends on the relative magnitudes of $(\alpha-\beta k)$ and $\left(4 \beta-\gamma^{2}\right)$, weighted by the parameter $\gamma$; the marginal impact of an increase in branding on the quantity demanded for product $Y$.

Under the assumptions discussed above, comparative static analysis can be used to gain theoretical insights into the process by which umbrella branding occurs. For example, an increase in per unit production costs has an ambiguous effect on the price charged for a particular product (i.e., $\frac{\partial P}{\partial C}=1-\frac{2 b}{4 b-f^{2}} \leq 0$ and $\left.\frac{\partial q}{\partial k}=1-\frac{2 \beta}{4 \beta-\gamma^{2}} \leq 0\right)$ because it lowers the baseline value for $\mathrm{P}$, but also (by virtue of reducing costs) also changes the effectiveness of pricing relative to branding, which facilitates an increase in P. Concomitantly, higher per unit production costs also require less branding to offset those costs (i.e., $\frac{d N}{d c} \leq 0$ and $\frac{d n}{d k} \leq 0$ ). An increase in consumer sensitivity to that price leads to lower prices (i.e., $\frac{\partial P}{\partial b} \leq 0$ and $\frac{\partial q}{\partial \beta} \leq 0$ ) as well as lower branding expenditures (i.e., $\frac{\partial N}{\partial b} \leq 0$ and $\frac{\partial n}{\partial \beta} \leq 0$ ). Higher exogenous demand for a product requires higher branding efforts and higher prices to sustain profitability (i.e., $\frac{d N}{d a} \geq 0, \frac{d n}{d \alpha} \geq 0, \frac{d P}{d a} \geq 0$, and $\frac{d q}{d \alpha} \geq 0$ ), which also comes with associated higher total costs (per unit costs times the quantity of output). If consumer sensitivity to 
branding increases, branding efforts also increase $\left(\frac{d N}{d f} \geq 0, \frac{d n}{d \gamma} \geq 0\right)$ to exploit greater reliance on the use of branding to manage demand for the product. Lastly, changes in consumer sensitivity to branding also allow the firm to charge higher prices (i.e., $\frac{d P}{d f} \geq 0, \frac{d q}{d \gamma} \geq 0$ ) as the branding is more effective in managing product demand.

\section{Case 2: Umbrella Branding}

In this case, the firm chooses $\mathrm{P}, \mathrm{q}, \mathrm{N}$ and $\mathrm{n}$ to maximize the following objective function:

$\Pi=\mathrm{w}^{*}\left[(\mathrm{P}-\mathrm{C}) *\left(\mathrm{a}-\mathrm{bP}+\mathrm{f}\left(\mathrm{N}^{0.5}+\mathrm{n}^{0.5}\right)\right)-\mathrm{N}\right]+(1-\mathrm{w})\left[(\mathrm{q}-\mathrm{k}) *\left(\alpha-\beta \mathrm{q}+\gamma\left(\mathrm{N}^{0.5}\right.\right.\right.$ $\left.\left.\left.+\mathrm{n}^{0.5}\right)\right)-\mathrm{n}\right]$

First order necessary conditions are:

$$
\begin{aligned}
& \frac{\delta \Pi}{\delta P}=w\left(a-2 b P+f\left(N^{0.5}+n^{0.5}\right)+b C\right)=0 \\
& \frac{\delta \Pi}{\delta N}=w\left(\frac{f(P-C) N^{-0.5}}{2}-1\right)+(1-w)\left(\frac{(q-k) \gamma N^{-0.5}}{2}\right)=0 \\
& \frac{\delta \Pi}{\delta q}=(1-w)\left(\alpha-2 \beta q+\gamma\left(N^{0.5}+n^{0.5}\right)+\beta k\right)=0 \\
& \frac{\delta \Pi}{\delta n}=w\left(\frac{f(P-C) n^{-0.5}}{2}\right)+(1-w)\left(\frac{(q-k) \gamma n^{-0.5}}{2}-1\right)=0
\end{aligned}
$$

The Hessian matrix is negative definite (ensuring that second order conditions hold) so long as, in addition to the signs of parameters assumed previously, the following conditions are met:

$2 b\left[\frac{P-C}{f}+\frac{(1-w) \gamma(q-k)}{w f^{2}}\right]>\sqrt{N}$

$2\left[\frac{w(P-C)}{f \gamma^{2}}+\frac{(1-w)(q-k)}{\gamma f^{2}}\right]>\left[\frac{w}{b \gamma^{2}}+\frac{(1-w)}{\beta f^{2}}\right] \sqrt{N}$

$w(1-w) b \beta(w f(P-C)+(1-w) \gamma(q-k))\left(N^{-1.5}+n^{-1.5}\right)>0$

Essentially, (20)-(22) (the second, third and fourth determinants of the Hessian matrix) require the firm to ensure that it is sufficiently profitable to fund its branding expenditures. The utility weights dictate the magnitude of profitability in each profit line that is used to fund branding. In other words, the weights characterize the degree to which one product line cross-subsidizes branding in the other profit line. In what follows we assume that these conditions hold, and we leave further analysis of these conditions as a suggestion for future research.

Solving for the four choice variables yields: 


$$
\begin{aligned}
& \mathrm{P}^{*}=\frac{2 w \beta f^{2} c-(1-w)\left(4 w \beta-\gamma^{2}\right)(a+b C)-(1-w) f \gamma(\alpha-k \beta)}{2\left(w \beta f^{2}-(1-w) b\left(4 w \beta-\gamma^{2}\right)\right)} \\
& N *=\frac{(1-w)^{2}(w f \beta(a-b C)+(1-w) b \gamma(\alpha-k \beta))^{2}}{\left(w \beta f^{2}-(1-w) b\left(4 w \beta-\gamma^{2}\right)\right)^{2}} \\
& \mathrm{q}^{*}=\frac{2(1-w) b \gamma^{2} k-w\left(4(1-w) b-f^{2}\right)(\alpha+k \beta)-w f \gamma(a-b c)}{2\left(w \beta f^{2}-(1-w) b\left(4 w \beta-\gamma^{2}\right)\right)} \\
& n *=\frac{w^{2}(w f \beta(a-b C)+(1-w) b \gamma(\alpha-k \beta))^{2}}{\left(w \beta f^{2}-(1-w) b\left(4 w \beta-\gamma^{2}\right)\right)^{2}}
\end{aligned}
$$

The intuition behind these results is similar, albeit using more complicated expressions, to the case in which no umbrella branding occurs. For each product line, the optimal price is based on average costs for that product line, plus an adjustment factor. However, there are two key differences between the non-umbrella branding and umbrella branding solutions. We first consider these differences using $\mathrm{P}$, the optimal price of the first product line. One difference is that the baseline for $\mathrm{P}$ is no longer simply average costs (C). Rather, $\mathrm{C}$ is adjusted by the factor $\frac{2 w \beta f^{2}}{2\left(w \beta f^{2}-(1-w) b\left(4 w \beta-\gamma^{2}\right)\right)}$, which expresses both the cross-subsidization of branding decisions (as noted by gamma in the denominator), as well as the profit motives of the firm (i.e., the term w). The second difference is that the adjustment factor beyond average cost $\left(\frac{-(1-w)\left(4 w \beta-\gamma^{2}\right)(a+b C)-(1-w) f \gamma(\alpha-k \beta)}{2\left(w \beta f^{2}-(1-w) b\left(4 w \beta-\gamma^{2}\right)\right)}\right)$ is also much more complicated expression, which includes both the firm's profit motives, umbrella branding for both product lines, and cost conditions for both product lines. Thus, the use of umbrella branding requires cross-subsidization and greater integration of production and marketing activities across product lines.

The intuition for the pricing of product line $\mathrm{Y}$ is analogous in interpretation. The baseline for $\mathrm{q}$ is no longer $\mathrm{k}$, but rather $\frac{2(1-w) b \gamma^{2}}{2\left(w \beta f^{2}-(1-w) b\left(4 w \beta-\gamma^{2}\right)\right)} \mathrm{k}$, which accounts for cross subsidization and profit motives. The adjustment factor beyond costs, $\frac{-w\left(4(1-w) b-f^{2}\right)(\alpha+k \beta)-w f \gamma(a-b c)}{2\left(w \beta f^{2}-(1-w) b\left(4 w \beta-\gamma^{2}\right)\right)}$, also reflects the need to cross-subsidize across product lines and more effectively integrate production and marketing.

These differences cumulatively suggest a slightly different outcome for pricing in the umbrella branding case. A perusal of the solutions for $\mathrm{P}$ and $\mathrm{q}$ indicate that, while in many situations pricing is based on average costs with a positive adjustment factor, there is no guarantee that this will hold true. Rather, it is entirely possible that the adjustment factors (beyond costs) for one of the product lines may be negative, which would, under most reasonable interpretations of parameter values, require the analogous adjustment factor for the other price to be positive. In other words, while pricing may reasonably be expected to be based around average cost, there is no guarantee that both products are priced at or above their respective average costs. It is entirely plausible that pricing in one market may be much higher than average costs, which then subsidizes lost profit in the other product line which may be priced below average economic costs. 
The solutions for $\mathrm{N}$ and $\mathrm{n}$ are unambiguously positive, as all terms in the numerators and denominators of these expressions are squared. Compared to the non-umbrella branding solutions, the solutions under an umbrella branding regime are more complicated, as branding expenditure decisions are based not just on one product line, but on a combination of cost and demand conditions across both product lines. As with the pricing solutions, the branding expenditure solutions suggest that an umbrella branding strategy requires greater integration of production and marketing activities across product lines.

It is also useful to examine how changes in parameter values (whether in discrete terms or using comparative static analysis) impact the model solutions. First, consider the utility weights placed on the profitability of each product line; that is, $w$ and $(1-w)$. Note that as $w$ approaches one (i.e., the firm places all of its emphasis on the profitability of $\mathrm{X}$ ), the solutions reduce to:

$\mathrm{P}^{*}=\mathrm{C}$

$N *=0$

$\mathrm{q}^{*}=\frac{-\gamma(a-b C)}{2 \beta f}+\frac{(\alpha+k \beta)}{2 \beta}$

$n *=\frac{((a-b c))^{2}}{f^{2}}$

Cleary, the firm prices at average cost and initiates no branding for product $\mathrm{X}$. Product line $\mathrm{Y}$ is financed through branding and its price is based on a weighted average of cost and demand conditions for both product lines.

Concomitantly, if $w$ approaches zero, the solutions reduce to and analogous situation in the opposite product lines:

$$
\begin{aligned}
& \mathrm{P}^{*}=\frac{(a+b C)}{2 b}+\frac{f(\alpha-k \beta)}{2 b \gamma} \\
& N *=\frac{(f \beta(a-b C)+b \gamma(\alpha-k \beta))^{2}}{\gamma^{2}} \\
& \mathrm{q}^{*}=k \\
& n *=0
\end{aligned}
$$

But in either case, or regardless of the value of w, the solutions for umbrella branding do not automatically reduce to solutions that are equivalent to the nonumbrella branding case. That is, the firm's proprietary objectives are intricately embedded in umbrella branding decisions. Perhaps more importantly, a comparison of (11)-(14) and (23)-(26) indicates that prices are neither unambiguously higher nor lower under umbrella branding versus the case where no umbrella branding occurs. The same holds true with regard to branding expenditures. It is only possible to infer that the levels are different, and the relative magnitudes of the model parameters dictate the difference.

With regard to comparative statics, there are two primary differences between the umbrella branding and the non-umbrella branding cases, both of which occur because marginal changes in one choice variable feedback through the rest of the solutions. One of these differences is that the feedback between the two demand 
structures makes some of the comparative statics non-zero. For example, consider the solution for the optimal prices P and q. In the non-umbrella branding case, an increase in per unit production costs have an ambiguous effect on the price charged for a specific product (i.e., $\frac{\partial P}{\partial C} \leq 0$ and $\frac{\partial q}{\partial k}>0$ ). Changes in another product line's costs tautologically do not impact pricing in the other product line (i.e., $\frac{d P}{d k}=0$, and $\frac{d q}{d c}=0$ ). But under the umbrella branding regime these comparative statics are generally not zero. If the denominators of (23) and (25) are assumed to be positive, $\frac{d P}{d k} \geq 0$, and $\frac{d q}{d c} \geq 0$, and the signs are reversed if the denominators of these expressions are negative.

Similarly, in the absence of umbrella branding, the demand for one product is unaffected by changes in consumer sensitivity to branding and/or the price in the other product line; that is $0, \frac{d n}{d b}=0$, and $\frac{d n}{d f}=0$

$$
\begin{aligned}
& \frac{d P}{d a}=0, \frac{d P}{d \beta}=0, \frac{d P}{d \gamma}=0, \frac{d N}{d a}=0, \frac{d N}{d \beta}=0, \frac{d N}{d \gamma}=0, \frac{d q}{d a}=0, \frac{d q}{d b}=0, \frac{d q}{d f}=0, \frac{d n}{d a}= \\
& 0, \frac{d n}{d b}=0, \text { and } \frac{d n}{d f}=0
\end{aligned}
$$

Regardless of the sign of $w \beta f^{2}-(1-w) b\left(4 w \beta-\gamma^{2}\right)$, that is no longer the case. The cumulative implication is that, by umbrella branding, the firm can effectively "smooth out" or cross-subsidize demand and cost conditions across its various product lines. If those costs are driven by uncertainty in resource markets, such behavior would be consistent with the use of umbrella branding to reduce product risk (Montgomery \& Wernerfelt 1992).

A second implication is that many of the comparative statics that are unambiguous in the non-umbrella branding case become ambiguous when umbrella branding is implemented. For example, the signs for $\frac{d P}{d \alpha}, \frac{d P}{d \beta}, \frac{d P}{d \gamma}, \frac{d N}{d \alpha}, \frac{d N}{d \beta}, \frac{d N}{d \gamma}, \frac{d q}{d a}, \frac{d q}{d b}, \frac{d q}{d f}, \frac{d n}{d a}, \frac{d n}{d b}$, and $\frac{d n}{d f}$, as noted above, are all zero in the non-umbrella branding case. But in the umbrella banding case, many of these comparative statics are generally ambiguous, regardless of the sign assumed for $w \beta f^{2}-(1-w) b\left(4 w \beta-\gamma^{2}\right)$. The implication arising from these comparative statics is that smoothing out cost and demand conditions comes with an opportunity cost. It becomes much more difficult to predict and/or assess how a change in demand or cost conditions impact the overall organization, because those changes have feedback effects throughout the other product lines.

\section{Practical Implications for Umbrella Branding}

Examination of the two models yields several interesting inferences that have practical implications for sport organizations such as Spokane Hoops. First, note that the weights allocated to the profitability of both product lines do not impact the solutions in the non-umbrella branding case, but are embedded in the umbrella branding case. This implies that profit status is fundamentally distinct from intentional decisions not to adopt umbrella branding, and firms with different profit status will continue to make similar branding decisions, so long as their product lines, cost conditions, and demand conditions, are similar. However, firms who make the decision to adopt umbrella branding do so with intentional consideration of their firm's objectives, and the degree to which they utilize 
umbrella branding is based on how much a firm values a particular product line relative to its other profit lines. This finding may provide some interesting testable hypotheses across firms with different profit status, which can be evaluated by future research. Firms that choose not to umbrella brand should have similar cost and demand conditions, regardless of profit status. Firms that choose to adopt umbrella branding (after controlling for demand and cost conditions) reveal unique information about their values and objectives based on that branding decision. More specifically, branding decisions reveal a "pecking order" of product lines that the firm values relatively more than others.

Second, while the intuition behind the solutions with, and without, umbrella branding are similar, the numerators and denominators are much more complicated with umbrella branding. Under umbrella branding, changes in one product line's market conditions impact those in other product lines. Thus, firms interested in pursuing an umbrella branding strategy are encouraged to adopt operations, strategic planning, and marketing research initiatives to ensure greater integration and coordination across all facets of the organization. Perhaps more importantly, firms should do so proactively to prepare for the opportunities and opportunity costs of these decisions. With regard to sport organizations such as Spokane Hoops, the decision to pursue umbrella branding is reasonable. Spokane Hoops is a relatively small organization, and a number of its product lines are seasonal in nature. For example, the Hoopfest tournaments located in Spokane and Las Vegas are implemented at different times of the year. Thus, it is reasonable to assign the same staff to market, implement and assess both events, which implicitly provides comprehensive integration across its product lines.

Third, umbrella branding across product categories or through brand extensions should enhance the equity of the parent brand. Subsidiary branding may certainly exhibit unique elements, but it must also enhance the umbrella brand. This can be achieved through positive consumer associations (risk perception reduction) and/or legal protections (limited financial liability). As a consequence, any existing or new product that exhibits highly variable quality, or whose characteristics deviate substantially from the remainder of the umbrella, would not be a good candidate for umbrella branding. For example, the initial expenses of incorporating Spokane Hoops as the umbrella brand for Hoopfest are likely to be quite high while the costs of branding the Amateur Athletic Union league, e.g. Spokane Hoops - AAU, (as well as the net profitability of that endeavor) may be quite low. There is little likelihood, however, that the new umbrella brand can confer significant name recognition benefits because it aligns with other initiatives under the current umbrella in terms of demand formation and costs. Even though the carryover in name recognition may be low, it may still make sense to implement the Spokane Hoops umbrella brand. Relating this point to our theoretical model, the interesting empirical issue is the specification for $\mathrm{U}$, both overall and its integration into product demands, and how that specification (including the magnitudes of those parameters involved) impacts the decision to pursue umbrella branding for some product lines, but not others. Within the context of Spokane Hoops, its product lines (which focus solely on basketball and infrastructure development to support basketball in the region) are relatively 
narrow in scope. So initiatives that do not have substantial name carryover likely impact the formation of $U$ in our model in a manner to contribute meaningfully to the umbrella brand. Concomitantly the formation of, say, a youth football league, may not be of sufficient name carryover to justify including it under the umbrella, even if it is a low cost endeavor.

\section{Conclusion}

The creation of an umbrella brand creates a new brand regardless of whether or not an effort is made to develop the brand. This holds true even when umbrella brand elements are only initially visible to investors and/or senior management, e.g. Berkshire Hathaway or DuPont. The current research inquiry begins to address the absence of research exploring the plausible effects associated with a sport organization creating an umbrella brand where one or more product lines may not be profit oriented.

Our findings are threefold. First, the decision to umbrella brand is distinct from the firm's objectives when the decision is not to pursue umbrella branding. Other considerations beyond profit status guide these decisions. But decisions to adopt umbrella branding inherently include profit status. Moreover, firm objectives guide the decision to adopt umbrella branding and an umbrella branding decision may reveal valuable information about the firm's pecking order of most valued brands. Second, our model suggests that a sport umbrella brand should only be used across product lines when the cost associated with branding an unprofitable product line are very low and the carryover benefits to the brand are quite high. Such benefits could accrue due to name recognition, quality perceptions, distinctiveness of the brand, and/or perceived relevance (Keller 2013). In other words, what matters in using an umbrella brand is the "fit" of the products under the umbrella, rather than the profitability each generates. Third, firms do need to cover their operating costs even if they are not strictly economic profit maximizing. Because umbrella branding integrates costs and demand structures across product lines, sport organizations must strategically change how they do business as they implement umbrella branding.

While the manuscript provides some interesting findings, it is intended as a first step to better understand umbrella branding in sport organizations. Our model is limited in several ways, which should be addressed in future research. Perhaps the most obvious limitation of the model is the simplicity with which branding and product demands were specified. Future research that uses more realistic, and complicated, specifications may obtain more accurate and precise inferences than were found in this analysis.

A second limitation of this analysis is in the interpretation of branding itself, as expressed in the model. This analysis assumed a static model, where branding was based merely on expenditures. Dynamic considerations, as well as the use of branding expenditures, was left unexplored. These assumptions have important implications for marketing. For example, a brand need not always reflect the name, or other brand elements, of the umbrella brand within a product category 
(branded house) or across product categories (house of brands). Products evolve over time, as does their branding. Hence, once a product is included in an umbrella brand, its contribution to the umbrella may increase or diminish over time. Future research that builds dynamic models that include past branding impacts and current market demand for joint products as well as substitute products, would provide insight into the evolution of umbrella branding, and as such provide a useful extension of our manuscript. Empirical analyses are also necessary (using both cross-sectional and time-series data) to test the predictions of these models, especially in cases where the theoretical models yield predictions that vary based on demand and cost conditions facing the firm(s) in question.

Any sport firm can always add an umbrella brand, which it may or may not emphasize. Such firms may compete with a variety of other producers who provide substitute products. These other producers may or may not be multiproduct firms or have umbrella brands (which they may or may not emphasize). This raises an interesting question that is left unaddressed by the current manuscript. Are all market participants aware of the new umbrella brand and how do they respond? As with the previous recommendation for future research, this question must be answered both theoretically and empirically.

Many other interesting questions could lead to useful extensions of our work. They include discerning how consumer prior beliefs determine whether or not existing brands of a sport organization and all competing brands are of either good or bad quality. Additionally, potential spillover effects to an umbrella brand from subsumed brands might also be expected when existing brand beliefs are favorable (brand is liked), well known (high levels of awareness), and viewed as consistent (little variation in product performance or probability of failure to meet expectations). Differentiation and relevance perceptions may be less likely to transfer from subsidiary brands to an umbrella brand, especially when production technologies and/or target markets for joint products are significantly different. Theoretical and empirical research to answer these (and other) questions are necessary to understand the competitive ramifications of umbrella branding in sport organizations.

\section{References}

Amrouche N, Rhouma TB, Zaccour G (2014) Branding decisions for retailer's private labels. Journal of Marketing Channels 21: 100-115.

Anonymous (2010) Loaned goals. Economist 395(8685): 67-68.

Bozman CS, Kurpis LV, Frye C (2010) Hoopfest: Using longitudinal economic impact data to assess the success of a strategic reorientation. Sport Management Review 13: 65-81.

Brook S (2005) Is the Dorfman-Steiner rule always optimal? The American Economist 49(2): 75-77.

Doherty A, Murray M (2007) The strategic sponsorship process in a non-profit sport organization. Sport Marketing Quarterly 16: 49-59.

Dube JP, Hitsch GJ, Manchanda P (2005) An empirical model of advertising dynamics. Quantitative Marketing and Economics 3: 107-144. 
Erdem T, Chang S (2012) A cross-category and cross-country analysis of umbrella branding for national and store brands. Journal of the Academy of Marketing Science 40(1): 86-101.

Friesner DL, Valente F, Bozman CS (2016) Using entropy-based information theory to evaluate survey research. Journal of Marketing Development and Competitiveness 10(3): 32-48.

Gartland D (2017) 3-on-3 basketball officially added to the 2020 Tokyo Olympics. Retrieved from https://on.si.com/2JXiqgI.

Hakenes H, Peitz M (2008) Umbrella branding and the provision of quality. International Journal of Industrial Organization 26: 546-556.

Keller KL (2013) Strategic brand management: building, measuring, and managing brand equity, $4^{\text {th }}$ ed. Boston, MA: Pearson.

Kesteloot K, Voet N (1998) Incentives for cooperation in quality improvement among hospitals - The impact of the reimbursement system. Journal of Health Economics 17: 701-728.

Kurpis LV, Bozman CS, Kahle LR (2010) Distinguishing between amateur sport participants and spectators: The list of values approach. International Journal of Sport Management and Marketing 7(3/4): 190-201.

Mills BM, Winfree JA (2016) Market Power, Exclusive Rights, and Substitution Effects in Sports. Antitrust Bulletin 61(3): 423-433. doi: 10.1177/0003603X16657228.

Montgomery CA, Wernerfelt B (1992) Risk reduction and umbrella branding. Journal of Business 65(1): 31-50.

Moorthy S (2012) Can brand extension signal product quality? Marketing Science 31(5): 756-770.

Neyland B (2018a) Fifth annual The Basketball Tournament announces partnership with Spokane Hoopfest. Retrieved from https://bit.ly/2I0SRcA. [Accessed 17 April 2018].

Neyland B (2018b) Spokane Hoops and USA Basketball team up for showdown. Retrieved from https://bit.ly/2ymqVAx. [Accessed 16 February 2018].

Ogden W (2018) Hoopfest develops partnership with The Basketball Tournament. Retrieved from https://bit.ly/2GA3eZ3. [Accessed 8 April 2018].

Pepall L, Richards D (2002) The simple economics of brand stretching. Journal of Business 75(3): 535-552.

Schnell L (2014) Hoopfest, the world's larget 3-on-3 tourney turns 25 this weekend. Retrieved from https://on.si.com/2MxFwfD. [Accessed 20 March 2018].

Thibault L, Slack T, Hinings B (1993) A framework for the analysis of strategy in nonprofit sport organizations. Journal of Sport Management 7(1): 25-43. 
